ISSN 0103-8478

\title{
ERRATA
}

Artigo originalmente publicado com ausência do nome da autora Maria Ligia de Arruda Mistieri

\section{Aspectos clínicos e concentração sérica da creatina-quinase e lactato-desidrogenase em cães submetidos à fisioterapia após atrofia muscular induzida}

Clinical aspects and serum concentration creatina kinase and lactate dehydrogenase in dogs submitted to physiotherapy after induced muscle atrophy

Soraia Figueiredo de Souza ${ }^{\mathrm{I}}$ João Guilherme Padilha Filho ${ }^{\mathrm{II}}$ Vera Maria Villamil Martins ${ }^{\mathrm{II}}$ Emílio de Almeida BelmonteII Nicole Maria Zanetti ${ }^{\mathrm{IV}}$ Luis Gustavo Gosuen Gonçalves Dias ${ }^{\mathrm{V}}$ Bruna Piva Maria" Letícia Abrahão Anai" ${ }^{\mathrm{II}}$ David José Miquelutti' ${ }^{\mathrm{III}}$

Maria Ligia de Arruda Mistieri ${ }^{\mathrm{VI}}$

Para html ou PDF, acesse, respectivamente:

http://www.scielo.br/scielo.php?script=sci_arttext\&pid=S0103-84782011000700024\&lng=pt\&nrm=iso\&tlng=pt

$\mathrm{Ou}$

http://www.scielo.br/pdf/cr/v41n7/a4611cr4215.pdf

'Centro de Ciências Biológicas e da Natureza, Universidade Federal do Acre (UFAC), 69915-900, Rio Branco, AC, Brasil. E-mail: soraiasouza@yahoo.com. Autor para correspondência.

IIDepartamento de Clínica de Pequenos Animais, Universidade Estadual Paulista (UNESP), Jaboticabal, SP, Brasil.

"IIUniversidade do Estado de Santa Catarina (UDESC), Lages, SC, Brasil.

${ }^{\mathrm{IV}}$ Médica Veterinária Autônoma, Centro Avançado de Veterinária (CAVET), Ribeirão Preto, SP, Brasil.

${ }^{\vee}$ Faculdade de Medicina Veterinária e Zootecnia de Garça (FAMED), Garça, SP, Brasil.

vIUniversidade Federal do Pampa (UNIPAMPA), Campus Uruguaiana, Uruguaiana, RS, Brasil. 